\title{
Resilience as an Important Soft Skill for Engineers' Work during the Covid-19 Pandemic
}

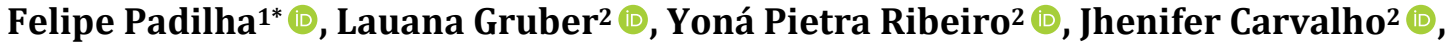 \\ Fernanda Hansch Beuren2 ${ }^{(\mathbb{C}}$, Alexandre Borges Fagundes $\left.{ }^{2}{ }^{(}\right)$, Delcio Pereira ${ }^{2}(\mathbb{C}$, \\ Débora Barni de Campos 2 (C)
}

\author{
${ }^{1}$ Department of Psychology, University of Itajai Valley, Itajaí, SC, Brazil \\ ${ }^{2}$ Department of Industrial Technology, State University of Santa Catarina, North Plateau Education Center, São Bento do Sul, SC, \\ Brazil \\ Email: ^felipe.padilha@edu.univali.br, ${ }^{\star} f k$.felipepadilhagmail.com
}

How to cite this paper: Padilha, F. Gruber, L., Ribeiro, Y. P., Carvalho, J., Beuren, F. H., Fagundes, A. B., Pereira, D., \& de Campos, D. B. (2021). Resilience as an Important Soft Skill for Engineers' Work during the Covid-19 Pandemic. Creative Education, 12, 2529-2534.

https://doi.org/10.4236/ce.2021.1211189

Received: August 19, 2021

Accepted: November 13, 2021

Published: November 16, 2021

Copyright $\odot 2021$ by author(s) and Scientific Research Publishing Inc. This work is licensed under the Creative Commons Attribution International License (CC BY 4.0).

http://creativecommons.org/licenses/by/4.0/

\begin{abstract}
This paper discusses the most important social skills for engineering professionals during the social distancing of the Covid-19 pandemic. A systematic literature review, in the Science Direct Scopus Web of Science databases, with subsequent classification of the articles captured by the Index Ordinatio algorithm, was carried out to understand the most important skills for engineering during the pandemic. The results pointed to resilience as the most important soft skill. Characteristics that make up emotional intelligence, such as adaptability and emotional growth, were also found. These soft skills are especially important in adverse conditions, such as the one imposed by the COVID-19 pandemic, which apply not only to individuals, but to organizations as a whole.
\end{abstract}

\section{Keywords}

Covid-19, Engineering, Resilience, Emotional Intelligence, Soft Skills

\section{Introduction}

In 2020, the Sars-Cov-2 (called Covid-19), pertaining to the Coronavirus family and which causes an acute respiratory system infection, caused a huge public health crisis around the world. The pandemic outbroke in China and, in a short time, spread to the rest of the world and reached a pandemic level.

These impacts could already be seen worldwide even within the first months after the first cases (Piwowar-Sulej, 2021). Within this context, many companies were forced to adapt their processes, suspend their activities, or even shut down. 
Similarly, many people were displaced to work remotely, having to deal with a new reality. Thus, different skills were required from professionals in all areas of knowledge.

Soft skills became particularly indispensable in this scenario, as these skills were often related to self-management and emotional intelligence (Campos et al., 2020).

In this context, the objective of the present work was to identify the most demanded soft skills for Engineers during the pandemic. This was done through a Systematic Literature Review (RBS) of the most relevant literature published worldwide to date and validated by researchers at the University of the State of Santa Catarina/Brazil (UDESC) and the University of Vale do Itajaí/Brazil (UNIVALI).

\section{Materials and Methods}

This research is based on the results collected from a Systematic Literature Review (RBS) applied in 2020, to understand the most significant soft skills for Engineering professionals during the Covid-19 pandemic.

A research was carried out in the Science Direct, Scopus and Web of Science databases, using the keywords (and respective derivations with similar meaning): Soft Skills (soft skills in engineering, engineer's soft skills); social isolation (social isolation, quarantine, social distancing and social isolation) and Covid-19 (Sars cov 2, Covid-19 and coronavirus). From these derivations, a combination of terms was performed, resulting in 15 forms of search, as shown in Table 1.

In total, 5893 documents were found, from which duplicates, congress articles, book chapters and event presentations were excluded, keeping only articles from scientific journals. Studies aligned with the scope were selected through titles and abstracts, resulting in a total of 416 articles.

After selecting the articles, the Methodi Ordinatio (Pagani el al., 2015) was applied. This method sorts the articles into a ranking of greater scientific relevance, taking into account the impact factor of the Journal Citation Reports, the year of publication and the number of citations in Google Scholar, as shown in Equation (1).

InOrdinatio $=(\mathrm{Fi} / 1000)+\alpha^{*}[10-($ Year_research-Year_publ $\left.)]+\Sigma \mathrm{Ci}\right)$

where:

Fi: Impact Factor, Journal Citation Report;

Year_research: Year of the research;

Year_publ: Year of publication;

Ci: Number of Google Scholar citations;

$\alpha$ : weight constant determined by the authors.In this research, its value was 10 for all journals.

Source: Pagani, Kovaleski, \& Resende (2015).

The creators of this method evaluate four other types of result ranking as available methodologies for bibliometric analysis, however, the method they 
Table 1. Systematic bibliographic review.

\begin{tabular}{|c|c|c|c|c|}
\hline \multirow[b]{2}{*}{ Keywords } & \multicolumn{3}{|c|}{ Database } & \multirow{2}{*}{$\begin{array}{c}\text { Total } \\
\text { number } \\
\text { of articles }\end{array}$} \\
\hline & $\begin{array}{c}\text { Science } \\
\text { Direct }\end{array}$ & Scopus & $\begin{array}{l}\text { Web of } \\
\text { Science }\end{array}$ & \\
\hline soft skills in engineering and social isolation & 617 & 152 & 0 & 769 \\
\hline soft skills in engineering and quarantine & 60 & 3 & 0 & 63 \\
\hline soft skills in engineering and social distance & 1415 & 957 & 4 & 2376 \\
\hline soft skills in engineering and social confinement & 66 & 15 & 0 & 81 \\
\hline soft skills in engineering and sars cov 2 & 14 & 9 & 0 & 23 \\
\hline soft skills in engineering and coronavirus & 27 & 32 & 0 & 59 \\
\hline soft skills in engineering and covid-19 & 25 & 22 & 0 & 47 \\
\hline engineer's soft skills and social isolation & 408 & 149 & 0 & 557 \\
\hline engineer's soft skills and quarantine & 39 & 2 & 0 & 41 \\
\hline engineer's soft skills and social distance & 783 & 963 & 0 & 1746 \\
\hline engineer's soft skills and social confinement & 47 & 1 & 0 & 48 \\
\hline engineer's soft skills and sars cov 2 & 8 & 7 & 0 & 13 \\
\hline engineer's soft skills and coronavirus & 22 & 32 & 0 & 54 \\
\hline engineer's soft skills and covid-19 & 14 & 2 & 0 & 16 \\
\hline Total Number of Results & 3545 & 2346 & 4 & 5893 \\
\hline
\end{tabular}

Source: Own authorship.

coined called Index Ordinatio proposes a simplification in relation to the time of result synthesis without losing the quality of the data obtained (Pagani, Kovaleski, \& Resende, 2015).

\section{Results and Discussion}

The recurrence of publications that address the soft skill Resilience in Engineering, using the keywords "resilience" and "Engineering", suggests that the Covid-19 pandemic was an important milestone in the increase in the index of scientific concern. The graphic in Figure 1 shows a considerable increase in research involving this soft skill in Engineering context in the Science Direct and Scopus databases in 2020 compared to previous years.

The scientific interest in "resilience" during the period of the Covid-19 pandemic was accentuated by dealing with a competency related to self-management, awareness, learning and flexibility, characteristics that are highly required during periods of quarantine, social isolation and so on. Factors imposed by the current pandemic (Ranasinghe, Jefferies, Davis, \& Pillay, 2020).

These impacts are measured in the personal and professional scope of the engineer, taking into account the resonances that the period imposed on daily work, both in socioeconomic aspects in the labor market (Papagiannidisa et al., 2020). 


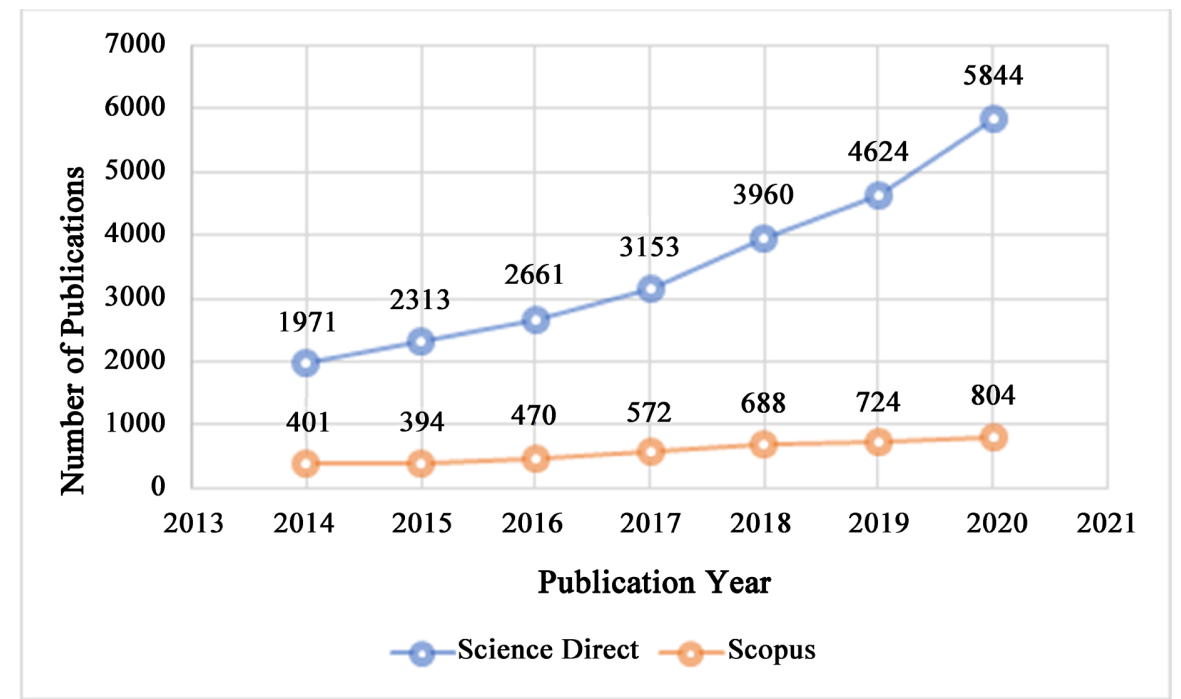

Source: Own authorship.

Figure 1. Publications per year.

During the analysis of the 44 articles, 8 of them significantly address the topic, and resilience is the most cited and scored out of the 23 soft skills found.

Among the important soft skills for engineering professionals, the term resilience, already known before the Sars Cov 2 outbreak, gained greater proportions in both personal and organizational contexts (Cheruvalath, 2019; Valli \& Vishnu, 2019; Papagiannidis et al., 2020).

For Saarikko et al. (2020), resilience has two applications in the Engineering professional context, both personal and within an organization scope. The latter refers to the adaptation and search for strategies under the adversities imposed by the pandemic. Both are correlated and directly linked to the professional involvement and commitment within the organization.

Not only are workers going through a maturing process in the face of the difficulties posed by the Covid-19 pandemic, but companies are also forced to adapt their processes, their culture and find strategic solutions to face new challenges. Within this adaptation, the knowledge, values and behaviors of stakeholders (both institutional and non-institutional) are involved in formulating appropriate risk reduction measures to increase resilience in a local context (Saarikko et al., 2020).

In the process of developing resilience as a competence, it is worth mentioning that human behavior itself is adaptive and complex as a result of environmental circumstances (Harrison \& Stergiou, 2015), as the human being and the environment in which they are inserted are in constant change.

As organizations reflect the human actions involved in their management, companies may want to consider how to increase business resilience across the organization. If someone is prepared for a pandemic without overloading the system, they will likely be able to respond to a much wider range of crises, including economic ones. Business resilience can be defined as a company's ability 
to anticipate, prepare for, respond and adapt to incremental changes and sudden interruptions in order to survive and prosper (Papagiannidisa et al., 2020).

One can observe the process of becoming resilient, for example, in the search for digital adaptation in processes that were previously done manually, in parallel with the adaptation of an entire team of employees to remote or blended work policies. All of these require resilience from Engineers, which is directly linked to creativity, critical and strategic thinking (Saarikko et al., 2020).

Engineers have always had to deal with complex challenges. However, a profound change has occurred in the last two decades with the realization of the need to shift from focusing on technical issues to sustainability issues that require an integrated, adaptive and participatory approach (Halbe et al., 2015), and that were further aggravated by the global situation imposed by the pandemic.

\section{Conclusion}

It is undeniable that several adversities have been faced during the pandemic around the world. It is interesting to notice the recurrence of scientific searches on resilience during this period, mainly applied to technical fields such as Engineering, which suggests that understanding human behavior and mental health within this context is a current trend in the scientific field.

Resilience is important in building relationships because humans, and societies as a whole, are always prone to impasses, paradigms, difficulties and challenging situations. In these moments, experiencing growth under adversity is essential, especially in chaotic situations that cross the world, such as the case of the Covid-19 pandemic.

Engineering was as crossed by the adversities experienced in the pandemic as any area of work. This study found in the research results of RBS articles that the Engineers and companies in the sector which have best developed and used resilience have so far been able to withstand more and better the storms of economic and social orders in comparison to those professionals and organizations that did not consider this skill.

\section{Conflicts of Interest}

The authors declare no conflicts of interest regarding the publication of this paper.

\section{References}

Campos, D. B., Resende, L. M. M. de, \& Fagundes, A. B. (2020). The Importance of Soft Skills for the Engineering. Creative Education, 11, 1504-1520.

https://doi.org/10.4236/ce.2020.118109

Cheruvalath, R. (2019). Does Studying “Ethics” Improve Engineering Students' Meta-Moral Cognitive Skills? Science and Engineering Ethics, 25, 583-596. https://doi.org/10.1007/s11948-017-0009-x

Halbe, J., Adamowski, J., \& Pahl-wostl, C. (2015). The Role of Paradigms in Engineering Practice and Education for Sustainable Development. Journal of Cleaner Production, 
106, 272-282. https://doi.org/10.1016/j.jclepro.2015.01.093

Harrison, S. J., \& Stergiou, N. (2015). Complex Adaptive Behavior and Dexterous Action. Nonlinear Dynamics, Psychology, and Life Sciences, 19, 345.

Pagani, R. N., Kovaleski, J. L., \& Resende, L. M. (2015). Methodi Ordinatio: A Proposed Methodology to Select and Rank Relevant Scientific Papers Encompassing the Impact Factor, Number of Citation, and Year of Publication. Scientometrics, 105, 2109-2135. https://doi.org/10.1007/s11192-015-1744-x

Papagiannidis, S., Harris, J., \& Morton, D. (2020). WHO Led the Digital Transformation of Your Company? A Reflection of IT Related Challenges during the Pandemic. International Journal of Information Management, 55, Article ID: 102166.

https://doi.org/10.1016/j.ijinfomgt.2020.102166

Piwowar-Sulej, K. (2021). Human Resources Development as an Element of Sustainable HRM-With the Focus on Production Engineers. Journal of Cleaner Production, 278, Article ID: 124008. https://doi.org/10.1016/j.jclepro.2020.124008

Ranasinghe, U., Jefferies, M., Davis, P., \& Pillay, M. (2020). Resilience Engineering Indicators and Safety Management: A Systematic Review. Safety and Health at Work, 11, 127-135. https://doi.org/10.1016/j.shaw.2020.03.009

Saarikko, T., Westergren, U. H., \& Blomquist, T. (2020). Digital Transformation: Five Recommendations for the Digitally Conscious Firm. Business Horizons, 63, 825-839. https://doi.org/10.1016/j.bushor.2020.07.005

Valli, S., \& Vishnu, P. (2019). Task-Based Approach to Develop the Writing Skills in English of Students at College Level. International Journal of Applied Engineering Research, 11, 2145-2148. 